\title{
ARTIKELEN
}

\section{Een complexe doelgroep en integraal samenwerken: hoe doe je dat?}

\section{Een cruciale mix van randvoorwaarden en competenties ${ }^{*}$}

\author{
Lisette Bitter, Violaine Veen \& Carmen Paalman
}

\section{Inleiding}

Jongvolwassenen (16-27 jaar) met politie- en justitiecontacten en problemen op meerdere leefgebieden vormen een complexe groep voor Nederlandse gemeenten. Deze groep is verantwoordelijk voor een onevenredig groot aandeel van de criminaliteit en maakt langdurig gebruik van verschillende gemeentelijke voorzieningen. Voor professionals zijn deze jongvolwassenen moeilijk te bereiken en te motiveren voor zorg- en/of strafrechtelijke trajecten. ${ }^{1}$ Sinds een aantal jaren wordt, binnen de zogenoemde Lokale Persoonsgerichte Aanpak (Lokale PGA), in veel gemeenten domeinoverstijgend samengewerkt om de complexe problematiek zoals bij deze jongvolwassenen te adresseren en adequate interventies in te zetten. De Lokale PGA betreft een integrale aanpak, toegesneden op de persoon en zijn systeem, waarbij een combinatie van bestuurlijke, strafrechtelijke, zorg- en overige interventies wordt ingezet. Geprobeerd wordt om hardnekkige patronen van criminaliteit en overlast te doorbreken en herhaling te voorkomen. ${ }^{2}$

De Lokale PGA wordt uitgevoerd onder gezag en verantwoordelijkheid van de burgemeester. Omdat de complexe problematiek van de Lokale PGA-doelgroep verband houdt met verschillende gemeentelijke portefeuilles (bijvoorbeeld Jeugd, Wmo, Werk \& Inkomen) zijn daar ook meerdere wethouders van de gemeente bij betrokken. Daarnaast spelen bestuurders van samenwerkingspartners een rol, zoals bestuurders van zorginstellingen, woningcorporaties en reclasseringsorganisaties. Zij stellen professionals en middelen voor de Lokale PGA beschikbaar. Doorgaans wordt door de gemeente een PGA-expert aangesteld om de integrale samenwerking vorm te geven. Onder leiding van de PGA-expert wordt de complexe casuïstiek, waarin zich zowel zorg- als veiligheidsproblemen voordoen, periodiek besproken met betrokken professionals. Casuïstiek kan voor de Lokale PGA

* Lisette Bitter is junior onderzoeker en projectcoördinator 'Startbaan' bij het lectoraat Kennisanalyse Sociale Veiligheid. Dr. Violaine Veen is hogeschooldocent bij het Instituut voor Social Work en senior onderzoeker bij het lectoraat Kennisanalyse Sociale Veiligheid. Dr. Carmen Paalman is hogeschooldocent bij het Instituut voor Social Work, senior onderzoeker bij het lectoraat Kennisanalyse Sociale Veiligheid en projectleider 'Startbaan'.

1 A.G. Donker \& C.H. Paalman, Kwetsbare jongeren en jongvolwassenen met justitiecontacten. Integraal naar een toekomstperspectief (subsidieaanvraag ZonMw), 2017.

2 Notitie Persoonsgerichte Aanpak (PGA) (Apothekerskast van Bureau RVS). 
worden aangemeld door samenwerkingspartners en andere eerstelijnsprofessionals. Een casus komt voor de Lokale PGA in aanmerking als er sprake is van meervoudige problematiek waarvoor een integrale aanpak vanuit twee of meer domeinen (bijvoorbeeld interventies vanuit het domein zorg en het domein veiligheid) noodzakelijk is.

Het lectoraat Kennisanalyse Sociale Veiligheid ${ }^{3}$ heeft in het kader van project 'Startbaan'4 onderzoek gedaan naar de integrale samenwerking binnen de Lokale PGA in Hilversum, Veenendaal, Wijk bij Duurstede en Zeist. Hieruit blijkt dat het organiseren van een dergelijke integrale aanpak ingewikkeld is vanwege de vele betrokken partijen in de samenwerking alsook door de complexe problemen die zich voordoen in de Lokale PGA-doelgroep. Ten eerste spelen bestuurders, vanwege de veelheid aan betrokken organisaties in de Lokale PGA, een belangrijke rol in de vormgeving van de samenwerking. Daarnaast heeft de PGA-expert een specifieke sleutelrol in het scheppen van een aantal randvoorwaarden voor een goede samenwerking en de uitvoering van de aanpak. Ten slotte vraagt het werken met complexe problematiek bij deze doelgroep om specifieke competenties van de betrokken professionals. In dit artikel wordt getracht antwoord te geven op de vraag wat er nodig is aan randvoorwaarden en competenties om integraal samen te werken in de Lokale PGA. Hiervoor worden de resultaten uit het onderzoek 'Startbaan' besproken en aangevuld met bevindingen uit de literatuur.

\section{Het onderzoek 'Startbaan'}

In het kader van het project 'Startbaan' zijn in 2018-2019 ruim zestig diepteinterviews afgenomen met professionals uit verschillende domeinen ${ }^{5}$ die betrokken zijn bij de Lokale PGA in vier gemeenten in Midden-Nederland. Daarnaast zijn vijftien casuïstiekbesprekingen geobserveerd, ter aanvulling op de interviews. Analyse van de verzamelde data leverde een overzicht op van de door de professionals ervaren knelpunten in de integrale samenwerking.

\section{Literatuuronderzoek}

Voor het schrijven van dit artikel is, ter aanvulling op de data uit het onderzoek 'Startbaan', naar literatuur gezocht over integrale samenwerking, waarbij gebruik is gemaakt van trefwoorden en de sneeuwbaltechniek in de online zoekmachines Academic Search en Google Scholar. Gezocht is naar recente (vanaf 2010) onderzoeksartikelen en publicaties met trefwoorden zoals: 'interdisciplinary collaboration', 'multidisciplinary practice', 'best practices', 'persoonsgerichte aanpak', en de Engelstalige dan wel Nederlandstalige overeenkomstige trefwoorden. Ook is gezocht op de namen van auteurs die actief zijn op het gebied van integrale samenwerking en/of persoonsgerichte aanpak, zoals 'T. van Yperen' en 'H. Bosselaar'. Er zijn acht relevante artikelen gevonden: deze artikelen zijn gericht op een

3 Dit lectoraat valt onder het Kenniscentrum Sociale Innovatie van Hogeschool Utrecht.

4 Dit project wordt mogelijk gemaakt door ZonMw, vanuit het programma 'Vakkundig aan het werk, integraal werken'.

5 Het betreft de domeinen veiligheid, zorg, werk en inkomen, onderwijs en huisvesting. 
integrale samenwerking tussen verschillende domeinen waarin de cliënt centraal staat.

In de onderhavige bijdrage komt allereerst de rol van de bestuurder in de vormgeving van de Lokale PGA aan bod. Vervolgens wordt de specifieke sleutelrol van de PGA-expert als procesregisseur van de aanpak nader toegelicht. Daarna worden de benodigde competenties van de betrokken professionals omschreven. Tot slot wordt getracht een antwoord te geven op de vraag wat nodig is om te kunnen samenwerken in de Lokale PGA.

\section{Rol van de bestuurder}

Visie

Voor veel betrokken professionals, zoals wijkagenten, jeugd-boa's, ggz-professionals en reclasseringsmedewerkers, behoren de werkzaamheden voor de Lokale PGA niet tot hun reguliere takenpakket. Zij gebruiken hiervoor tijd van de eigen organisatie, waardoor hun betrokkenheid bij de Lokale PGA onder druk komt te staan zodra de werkdruk toeneemt of hun leidinggevende het nut en de noodzaak van de integrale samenwerking rond deze complexe doelgroep niet inziet. Zo zijn ggz-professionals betrokken bij casusoverleggen waar ook jongvolwassenen worden besproken die niet bij hen in behandeling zijn, maar voor wie zij wel meedenken in de Lokale PGA-aanpak. Voor deze advieswerkzaamheden ontvangen zij geen financiering, omdat de zorgverzekeraars alleen kosten vergoeden voor cliënten die in behandeling zijn. Voor borging van de Lokale PGA is het daarom cruciaal dat bestuurders van alle samenwerkingspartners de noodzaak en het nut van de integrale samenwerking inzien. Het vraagt om een duidelijke visie op de overeengekomen aanpak van de doelgroep. De complexe casuïstiek vraagt doorgaans om extra tijdsinvestering van de betrokken professionals. Naast dat er bij deze doelgroep vaak complexe problemen op meerdere leefgebieden spelen, bijvoorbeeld op het gebied van verslaving, geestelijke gezondheid en huisvesting, zijn deze jongvolwassenen ook vaak al eerder (mogelijk negatief) in aanraking geweest met hulpverlening. Het vraagt extra tijd van de professionals om hen gemotiveerd te krijgen om mee te werken. ${ }^{6}$ Daarnaast zijn de reguliere interventies niet afdoende voor deze doelgroep. Het kost tijd om gezamenlijk acties te bepalen en passende interventies in te zetten. Bovendien wordt het resultaat hiervan soms niet of pas na een langere periode zichtbaar. Dit vraagt om bestuurlijk commitment en een andere manier van verantwoorden, waarbij er meer oog is voor de maatschappelijke kosten en effecten. ${ }^{7}$ Het vraagt ook om een andere wijze van sturing door bestuurders. In plaats van sturing op 'output' (bijvoorbeeld het aan-

6 H. Bosselaar e.a., Multiproblematiek bij cliënten. Verslag van een verkenning in relatie tot (arbeids)participatie, Den Haag: Ministerie van Sociale Zaken en Werkgelegenheid 2010.

7 KPMG, Vernieuwing in het sociaal domein. Samen aan de slag met verantwoording, 2019. 
tal geholpen cliënten) zouden bestuurders zich meer moeten richten op 'outcome' (het stimuleren en versterken van de beoogde maatschappelijke opbrengsten). ${ }^{8}$

\section{Formaliseren betrokkenheid}

Het is essentieel dat bestuurders van samenwerkingspartners de betrokkenheid van hun medewerkers bij de Lokale PGA formaliseren, waarbij een duidelijke beschrijving van verantwoordelijkheden en structurele kenmerken (zoals caseload en de mogelijkheid om te reflecteren op de samenwerking en resultaten) gegeven wordt. ${ }^{9}$ Bestuurders dienen heldere afspraken te maken over de vorm, de wijze van financiering en de inzet van professionals en middelen, maar ook over het doel van de Lokale PGA, de definitie van de doelgroep en wanneer de Lokale PGAaanpak als succesvol wordt beschouwd. ${ }^{10}$

\section{Sturing}

Als er een duidelijke visie op de doelgroep is gevormd en het kader staat, dan is het aan de bestuurders om hierop te sturen. Uit zowel het Startbaan-onderzoek als de literatuur komt het belang van sturen op monitoren en evalueren naar voren. ${ }^{11}$ Hierbij gaat het om het monitoren en evalueren van de samenwerking en de resultaten. De uitkomsten hiervan vormen de basis voor het waarborgen en zo nodig bijstellen van het Lokale PGA-proces. Daarnaast geeft het inzicht in de impact die de samenwerking op de professionals heeft en brengt het verbeterpunten naar voren. Belangrijk hierbij is dat bestuurders niet alleen 'bottom-up' knelpunten oplossen, maar ook 'top-down' richting geven. Het moet zich dus niet beperken tot intentieverklaringen of afspraken over middelen, maar bestuurders kunnen ook veranderingen doorvoeren als het gaat om interne prioriteiten of werkprocessen. ${ }^{12}$

\section{Rol van de PGA-expert}

\section{Realisatie kader}

Als het kader voor de Lokale PGA samen met de bestuurders is vastgesteld, is het aan de PGA-expert om de aanpak vorm te geven. Doordat er bij deze jongvolwassenen vaak problemen op meerdere domeinen spelen, is betrokkenheid vanuit meerdere samenwerkingspartners bij de Lokale PGA nodig. Over het algemeen zijn bij een casus professionals vanuit de domeinen zorg (wijkteam, ggz, jeugdbescherming, ambulante begeleiding vanuit hulpverleningsinstellingen), huisves-

8 Q. van der Zijden \& K. Diephuis, Handreiking Integrale Zorg. Samenwerken rond jeugd met meervoudige problematiek en hun gezin, GGZ Nederland/Jeugdzorg Nederland/Landelijk Expertise Centrum Speciaal Onderwijs/Vereniging Gehandicaptenzorg Nederland/Vereniging Orthopedagogische Behandelcentra 2012.

$9 \quad$ E. Verheijden \& M. de Lange, Wat werkt bij integrale jeugdhulp, NJI 2016.

10 Van der Zijden \& Diephuis 2012.

11 Verheijden \& De Lange 2016; Van der Zijden \& Diephuis 2012; E. Vestergaard \& B. Nørgaard, 'Interprofessional collaboration. An exploration of possible prerequisites for succesful implementation', Journal of Interprofessional Care 2018, 2.

12 Van der Zijden \& Diephuis 2012. 
ting, werk en inkomen, leerplicht en veiligheid (wijkagent, boa, adviseur Veiligheid) betrokken.

Naast het betrekken van samenwerkingspartners moeten er met de betrokken professionals afspraken worden gemaakt over de werkwijze en de werkprocessen. Aangezien er bij integrale samenwerkingsverbanden geen sprake is van een hiërarchische organisatiestructuur, moeten er duidelijke afspraken gemaakt worden om tot een structurele werkwijze te kunnen komen. Te denken valt aan het doel van het samenwerkingsverband, een duidelijke rol- en taakverdeling (afstemmen wie het directe aanspreekpunt voor de jongvolwassene is, dit kan per casus verschillen), communicatieafspraken (wanneer licht men elkaar in en op welke manier) en het opzetten van een overlegstructuur. ${ }^{13}$ Uit het Startbaanonderzoek komt naar voren hoe complex het vormgeven van deze processen is. In alle vier gemeenten kwamen knelpunten naar voren die betrekking hebben op het organiseren van de werkprocessen. Zo zocht een gemeente naar een overlegstructuur waarbij professionals goed aangesloten bleven, maar de werkdruk niet nog meer verhoogd werd. Een andere gemeente was zoekende naar een geschikte manier waarop professionals die niet direct bij de casus betrokken waren, toch betrokken konden worden voor een adviesfunctie.

Naast dat er veel verschillende professionals bij een Lokale PGA-aanpak betrokken zijn, hebben deze professionals uit het zorg- en veiligheidsdomein ook regelmatig te maken met noodsituaties bij cliënten c.q. inwoners. Hierdoor is het voor hen nog moeilijker om tijd te vinden en dan ook in die afgesproken tijd beschikbaar te zijn. Voor een goede integrale samenwerking en om mogelijke moeilijkheden te overbruggen is het belangrijk om heldere procedures op te zetten die onderling contact en effectieve communicatie faciliteren, bijvoorbeeld het kunnen inzetten van een vervanger. ${ }^{14}$

\section{Implementatie methodisch werken}

Uit het Startbaan-onderzoek blijkt dat professionals behoefte hebben aan een meer gestructureerde werkwijze met een integraal plan van aanpak waarin beschreven wordt wat het doel is, welke acties daartoe ondernomen moeten worden en wie waarvoor verantwoordelijk is. Professionals uit een deelnemende gemeente gaven tijdens een Startbaan-bijeenkomst aan dat zij het gevoel hadden vooral geleid te worden door de ontwikkelingen in een casus, of zoals zij het noemden: 'brandjes blussen'. Door het direct handelen naar de actuele situatie in een casus is het voor hen minder duidelijk aan welke structurele doelen gewerkt wordt. Professionals wilden graag meer proactief in plaats van reactief te werk gaan. In drie gemeenten was behoefte aan een meer methodische werkwijze, waarbij het in kaart brengen van de problematiek en het monitoren en evalueren binnen een casus op een structurele manier gebeuren.

Voor de vier deelnemende gemeenten in het Startbaan-onderzoek zijn samen met professionals stappenplannen voor de gekozen knelpunten opgesteld. Bij iedere

13 Van der Zijden \& Diephuis 2012.

14 M. Layalants, 'Multidisciplinary Collaboration in Child Protective Clinical Consultations. Perceptions of Best Practices', Journal of Public Child Welfare 2013, 7. 
gemeente werd het onderdeel 'Zorg voor een doelmatige en planmatige samenwerking' als gewenste implementatie bepaald. Hiervoor werd de Zelfredzaamheid-Matrix $^{15}$ (ZRM) als instrument geadviseerd. Dit instrument maakt inzichtelijk op welke leefgebieden zich problemen voordoen, waarna er acties aan de betrokken professionals toegewezen kunnen worden. Het geeft ook mogelijkheden voor monitoring en evaluatie: zijn er, tijdens en na het PGA-traject, (positieve) veranderingen op de verschillende leefgebieden? Bureau RVS ${ }^{16}$ heeft naar aanleiding hiervan een PGA-monitor ontwikkeld, op basis van de ZRM. Deze monitor wordt binnenkort bij de gemeenten in Midden-Nederland geïmplementeerd.

Ook uit de literatuur komt naar voren dat doelbepaling, duidelijke rol- en taakverdeling en monitoring en evaluatie belangrijke randvoorwaarden zijn voor integrale samenwerking. Hoe concreter het gezamenlijke doel en hoe duidelijker de meerwaarde voor alle betrokkenen is, hoe gemakkelijker het is om commitment te krijgen en te behouden. Door na afloop te meten of de beoogde effecten zijn behaald, wordt inzichtelijk wat de gezamenlijke inspanningen hebben opgeleverd. Hiervoor zijn een nulmeting en continue monitoring van de resultaten van belang. ${ }^{17}$ De PGA-expert is verantwoordelijk voor het realiseren van de monitoring en effectmeting in de praktijk en het voeren van de regie hierop.

\section{Competenties}

De combinatie van integraal samenwerken en de complexiteit van de doelgroep in de Lokale PGA betreft een dubbele uitdaging die vraagt om specifieke competenties van professionals. Zoals verwoord door een respondent uit het Startbaanonderzoek: 'Iedereen moet maar integraal kunnen werken en wat ik gemerkt heb de afgelopen jaren dat ik dit doe, is dat integraal werken een kwaliteit is die je wel of niet in je gereedschapskistje hebt als professional.' In deze paragraaf worden eerst de competenties besproken die voor de rol van een PGA-expert van belang zijn. Vervolgens wordt ingegaan op belangrijke competenties van de betrokken professionals bij de Lokale PGA in het algemeen.

\section{Leiderschapsvaardigheden PGA-expert}

Sterk leiderschap wordt in de literatuur als een essentieel onderdeel gezien van een succesvolle multidisciplinaire samenwerking, ${ }^{18}$ zowel op organisatorisch niveau (het opzetten van een samenwerkingsstructuur en het zorgen voor benodigde middelen) als op individueel niveau (het creëren van een goede, productieve werkomgeving). Het type leiderschap is dan ook bepalend voor een succesvolle

15 www.zelfredzaamheid-matrix.nl.

16 Een samenwerkingsverband in Midden-Nederland van 39 gemeenten, politie en Openbaar Ministerie.

17 Van der Zijden \& Diephuis 2012; Verheijden \& De Lange 2016.

18 Van der Zijden \& Diephuis 2012; Verheijden \& De Lange 2016; Vestergaard \& Nørgaard 2018; Layalants 2013. 
integrale samenwerking. ${ }^{19}$ Samenwerkingsverbanden hebben meestal een niethiërarchische structuur, wat vraagt om een coördinatie die gericht is op het faciliteren en versterken van de samenwerking. Het type leidinggevende dat daarbij past dient sensitief te zijn voor verhoudingen en weinig 'machtsgedrag' te vertonen, omdat samenwerking niet afdwingbaar is. ${ }^{20}$

De PGA-expert is verantwoordelijk voor het vormgeven van een succesvol samenwerkend team. In het Startbaan-onderzoek werden de volgende gedragingen van de PGA-expert in verband gebracht met een succesvolle samenwerking: het zorgen voor een duidelijk kader en procedures, regievoering, zichtbaarheid, bereikbaar en beschikbaar zijn voor vragen, afstemming en terugkoppeling van de verrichte handelingen en resultaten in een casus. Daarnaast komt zowel uit het Startbaan-onderzoek als uit de literatuur naar voren dat een sterke leider ook een motivator en een verbinder is. Volgens Lalayants is integrale samenwerking te vergelijken met een orkest: je kunt alle partijen bij elkaar zetten en dan maken zij vooral veel geluid, maar het heeft een dirigent nodig om er harmonieuze muziek van te maken. ${ }^{21}$

\section{Communicatieve en sociale vaardigheden PGA-expert}

Een PGA-expert dient over sterke communicatieve vaardigheden te beschikken. Motiveren en verbinden vergt duidelijke communicatie over een gedeelde urgentie, onderlinge afhankelijkheid (iedereen draagt deskundigheid bij om doelen te bereiken) en een gemeenschappelijk eigenaarschap van doelen en visie. Goede luistervaardigheden en inlevingsvermogen van de PGA-expert zijn nodig om professionals uit verschillende disciplines en domeinen bij elkaar te brengen en in een gezamenlijke aanpak te betrekken.

Niet alleen de PGA-expert dient over goede communicatieve en sociale vaardigheden te beschikken, ook alle betrokken professionals dienen over eigenschappen te beschikken die teamvorming bevorderen. Wederzijds respect voor ieders visie, uitgangspunten, doelen, verantwoordelijkheden en bevoegdheden is van belang. Voor een succesvolle samenwerking dient men mét elkaar te werken in plaats van naast elkaar. Hiervoor is een open en gelijkwaardige communicatie tussen teamleden nodig. ${ }^{22}$ Binnen een goede samenwerking geven professionals elkaar feedback en kritiek en blijft de houding naar elkaar toe positief.

Voor het bewerkstelligen van een succesvolle samenwerking wordt ook de term 'building shared identity' genoemd. ${ }^{23}$ Elke groep professionals heeft een eigen identiteit en neemt een eigen organisatiecultuur mee, bestaande uit professionele waarden, regels en taal. Het is van belang dat professionals goed geïnformeerd aan de samenwerking beginnen, zodat zij op de hoogte zijn van de vaardigheden en expertise van de andere betrokken professionals. Er wordt aanbevolen om bij elkaars werk mee te lopen om de verschillende werkwijzen van samenwerkings-

19 T. van Yperen \& R. Hageraats, Leiding geven aan transformatie, Utrecht: Nederlands Jeugdinstituut 2018.

20 Van der Zijden \& Diephuis 2012.

21 Layalants 2013.

22 Verheijden \& De Lange 2016.

23 Layalants 2013. 
partners te leren kennen en om samen trainingen te volgen. Op deze manier wordt voor samenwerkingspartners duidelijk dat er verschillende perspectieven en invalshoeken zijn van waaruit gewerkt wordt met dezelfde doelgroep, en dat verschillende zienswijzen naast elkaar mogen bestaan. Dit is een eerste stap in de richting van het ontwikkelen van een gezamenlijke, nieuwe gedeelde identiteit. Om de samenwerking goed af te kunnen stemmen worden vervolgens het gezamenlijke doel en hoe men elkaar daarin kan aanvullen meer van belang dan de verschillende perspectieven en werkwijzen: samenwerkingspartners richten zich meer op wat van belang is voor de jongvolwassene en ontwikkelen daarvoor een nieuwe set professionele waarden, regels en taal. Uit het Startbaan-onderzoek kwam in dit verband het volgende naar voren: 'Professionals dienen niet alleen kennis te hebben van de verschillende domeinen, maar moeten er ook voor open staan en bereid zijn een stapje opzij te doen als een ander doel prevaleert boven het doel van de eigen organisatie. Zij moeten in staat zijn om de repressieve "harde" aanpak te combineren met het bieden van de helpende hand. Ook moeten zij het een uitdaging vinden om de samenwerking met andere partijen te vinden en samenwerkingsafspraken te maken.'

\section{Specifieke vaardigheden met betrekking tot de Lokale PGA-doelgroep}

Om integraal samen te kunnen werken rond een complexe doelgroep zoals die van de Lokale PGA dient een professional over specifieke kennis en vaardigheden te beschikken en bovenal affiniteit te hebben met de doelgroep. Specifieke kennis beslaat voornamelijk (vak)inhoudelijke kennis over de doelgroep, kennis over problematiek op meerdere leefgebieden en interventiemogelijkheden. Naast vakinhoudelijke kennis dienen professionals echter ook over specifieke vaardigheden te beschikken die aansluiten op de Lokale PGA-doelgroep én integraal samenwerken. Volgens Van der Zijden en Diephuis beschikt het type professional dat hiervoor het meest geschikt is over een pioniersgeest die boven het eigen specialisme kan staan in denken en handelen: een professional die problematiek en casuïstiek met anderen deelt en een creatieve en oplossingsgerichte houding heeft. ${ }^{24}$ Resultaten uit het Startbaan-onderzoek sluiten hierop aan: creativiteit voor het bedenken van oplossingen, buiten de kaders kunnen kijken (out of the box), overzicht houden en snel en flexibel kunnen schakelen, zijn door veel respondenten genoemde essentiële eigenschappen voor Lokale PGA-professionals. Maar ook meer algemene eigenschappen worden genoemd: vasthoudendheid om resultaten te bereiken, stevig in de schoenen staan, emotioneel niet te betrokken raken, om kunnen gaan met tegenslagen en situaties die plotseling veranderen, geduld opbrengen en duidelijk en integer zijn.

Eigenschappen zoals creativiteit, flexibiliteit en 'out of the box'-denken zijn geen vaardigheden waarover iedere professional zomaar beschikt, hetgeen aansluit bij het citaat aan het begin van deze paragraaf. Dit pleit voor een werkwijze waarin de meest geschikte professional vanuit een samenwerkingspartner wordt 'gematcht' aan de Lokale PGA. Daarnaast dient ook het belang van het ontwikkelen van vaardigheden om effectief samen te werken met een complexe doelgroep 
niet onderschat te worden. Onderzoek uit de medische sector laat zien dat studenten die tijdens hun opleiding getraind worden om samen te werken in multidisciplinaire teams, wel degelijk vaardigheden en een juiste houding ontwikkelen die nodig zijn om effectief samen te werken in een team met andere zorgprofessionals. ${ }^{25}$ Integraal samenwerken met een complexe doelgroep vraagt om een specifiek pakket aan competenties van een professional, waarvan een deel al ontwikkeld zou kunnen worden tijdens de opleidingen waar veel PGA-professionals uitstromen (bijvoorbeeld Sociaal Werk, Integrale Veiligheidskunde, Sociaal Juridische Dienstverlening, Maatschappelijk Werk en Dienstverlening).

\section{Conclusie}

Uit zowel het Startbaan-onderzoek als de literatuur komt naar voren dat een cruciale mix van (organisatorische) randvoorwaarden en competenties nodig is om samen te kunnen werken in de Lokale PGA. Allereerst is het van belang dat bestuurders een duidelijke visie ontwikkelen op de Lokale PGA en de rol van hun organisatie daarin. Resultaten van de aanpak voor een doelgroep die zich kenmerkt door complexe problemen zijn soms niet of pas op de langere termijn zichtbaar. Dit vraagt van organisaties en hun bestuur om een lange adem en een visie die gericht is op de maatschappelijke kosten en opbrengsten. Naast heldere afspraken over de inzet van mensen en middelen dienen bestuurders dus afspraken te maken over het doel van de Lokale PGA, de definitie van de doelgroep en wanneer de Lokale PGA-aanpak als succesvol wordt beschouwd.

Ten tweede speelt de PGA-expert, als procesregisseur van de aanpak, een belangrijke rol. Aangezien er geen sprake is van een hiërarchische organisatiestructuur, is het aan deze professional om de aanpak in de gemeente vorm te geven. Het belang van het neerzetten van een duidelijke structuur komt uit de literatuur als randvoorwaarde naar voren. Ook het Startbaan-onderzoek toont het belang van een gestructureerde werkwijze aan, waarin methodisch gewerkt wordt (bijvoorbeeld door het gebruik van een instrument zoals de Zelfredzaamheid-Matrix) en waarin resultaten gemonitord en geëvalueerd worden. Daar moeten heldere procedures voor zijn, die onderling contact en effectieve communicatie faciliteren. In de praktijk is de PGA-expert er verantwoordelijk voor om deze werkprocessen vast te leggen en aan te sturen.

Tot slot vraagt integraal samenwerken rond deze complexe doelgroep om specifieke competenties. Als verantwoordelijke voor het vormgeven van de Lokale PGA dient de PGA-expert over sterke leiderschapskwaliteiten te beschikken en op sensitieve wijze een samenwerkend team bij elkaar te brengen. Daar zijn communicatieve en sociale vaardigheden voor nodig: duidelijke communicatie over het gemeenschappelijke doel en de manier van werken. Goede luistervaardigheden en inlevingsvermogen zijn nodig om professionals uit verschillende organisaties in een gezamenlijke aanpak te betrekken.

25 J. de Vries-Erich e.a., 'Identifying facilitators and barriers for implementation of interprofessional education. Perspectives from medical educators in the Netherlands', Journal of Interprofessional Care 2017, 2. 
Ook voor alle betrokken professionals in de Lokale PGA geldt dat er specifieke competenties nodig zijn. Naast vakinhoudelijke kennis dienen PGA-professionals over vaardigheden te beschikken die aansluiten op de Lokale PGA-doelgroep én integraal samenwerken. Een creatieve, oplossingsgerichte en op samenwerking gerichte houding wordt daarvoor als essentieel gezien, wat pleit voor het matchen van de meest geschikte professional vanuit een samenwerkingspartner aan de Lokale PGA. Ook zou er binnen opleidingen waar veel PGA-professionals uitstromen aandacht moeten zijn voor het ontwikkelen van samenwerkingsvaardigheden.

De afgelopen jaren is kennisontwikkeling voor wat betreft de organisatorische randvoorwaarden en benodigde competenties van professionals bij het integraal samenwerken toegenomen. Over de effectiviteit van samenwerkingsverbanden, in het bijzonder gericht op een complexe doelgroep zoals die van de Lokale PGA, is echter weinig bekend. Meer onderzoek naar de opbrengsten van de Lokale PGA en naar wat werkt voor wie, wanneer en waarom is gewenst, zodat de mix van randvoorwaarden en competenties uitgewerkt kan worden naar onderbouwde werkzame elementen. 